\title{
A very rare case of submucosal invasive duodenal adenocarcinoma in a patient with a history of radiation therapy
}

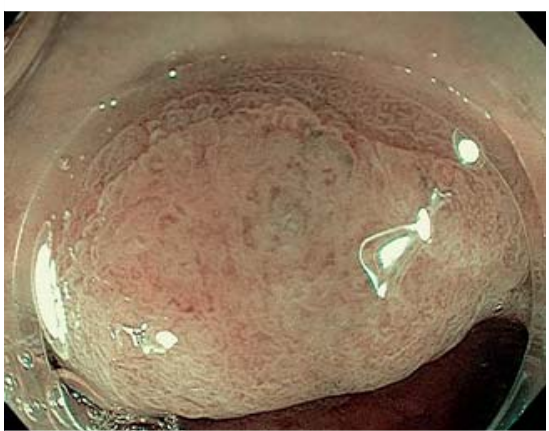

- Fig. 1 Endoscopic narrow-band imaging view of the lesion that was situated in the duodenal bulb.

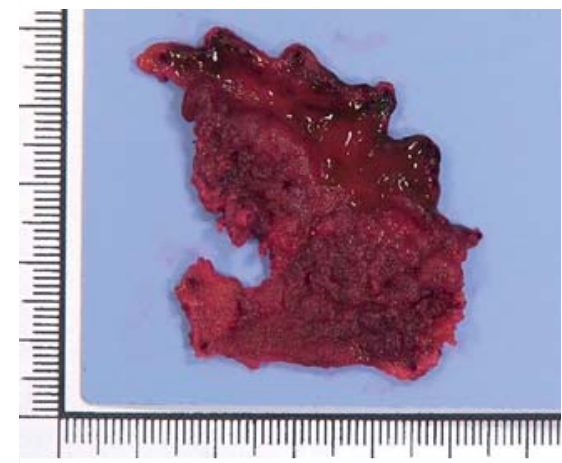

- Fig. 2 Macroscopic appearance of the 4-cm specimen resected by endoscopic submucosal dissection.

Adenocarcinomas of the small intestine are rare compared with other gastrointestinal carcinomas. They are mostly found situated in the duodenum. Despite an increasing incidence of duodenal carcinomas in recent decades, most such lesions are either intramucosal or deep invasive carcinomas; intermediate invasive cancers in the submucosa are extremely rare, having been described only in a few cases in the Japanese language [1, $2]$. Because of the rarity of their incidence, the exact risk of lymph node recurrence for these submucosal tumors is unknown. Therefore, the importance of $\mathrm{R} 0$ resection by endoscopic submucosal

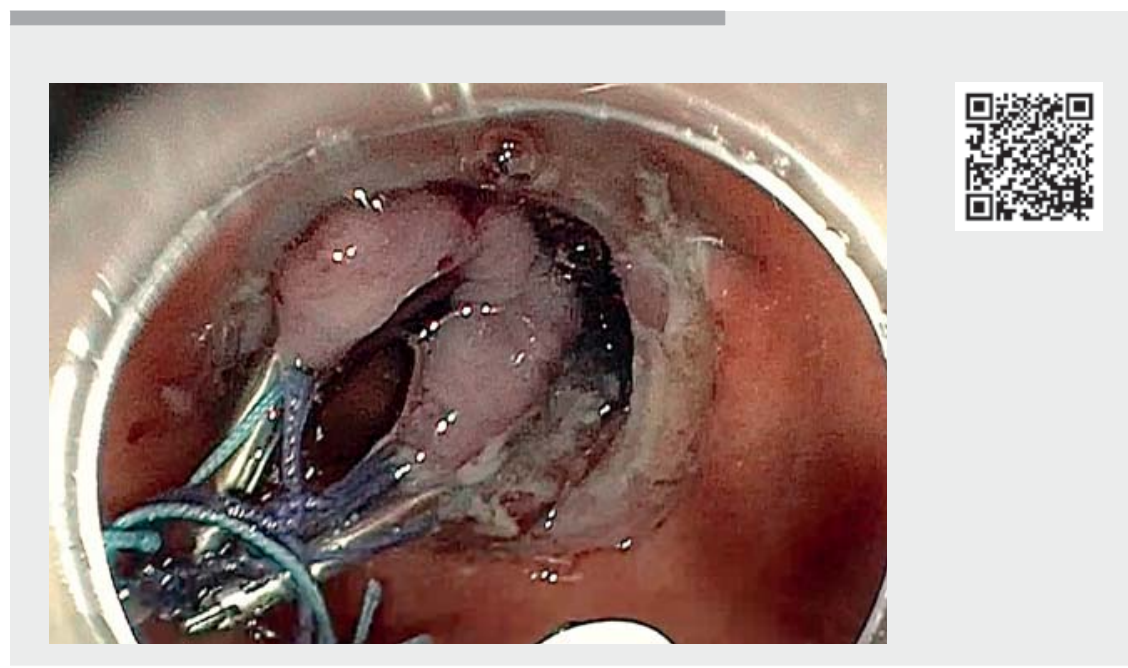

Video 1 Resection by endoscopic submucosal dissection of a submucosal invasive duodenal carcinoma.

dissection to obtain a perfect histological assessment is debatable as submucosal invasion usually leads to salvage surgery being performed. In our patient, who had a past history of radiation therapy, endoscopic submucosal dissection was performed ( $\triangleright$ Fig. 1 ; $\triangleright$ Video 1 ), and histological assessment revealed a well-differentiated adenocarcinoma invading the submucosa to a depth of $250 \mu \mathrm{m}$ ( $\triangleright$ Fig.2), without any evidence of lymphovascular invasion or tumor budding. This case illustrates that, although the model of the adenoma-carcinoma sequence is believed to apply to the small intestine, as well as to the large intestine, submucosal invasive duodenal carcinomas are extremely rare. In our case, we could not identify an area of abnormal pit pattern suspicious for deep invasion. The patient's history of radiation therapy could also have facilitated the invasion of this tumor into the submucosa.

Endoscopy_UCTN_Code_CCL_1AB_2AZ_3AB

\section{Competing interests}

The authors declare that they have no conflict of interest.

The authors

Pierre Lafeuille, Jérôme Rivory, Thomas Lambin, Paul Bonniaud, Thierry Ponchon, Florian Rostain, Mathieu Pioche Department of Endoscopy and Hepatogastroenterology, Pavillon L, Edouard Herriot Hospital, Lyon, France

Corresponding author

\section{Pierre Lafeuille, MD}

Endoscopy unit - Digestive Disease department, Pavillon L - Edouard Herriot Hospital, 69437 Lyon, France pierre.lafeuille@chu-lyon.fr 
Bibliography

[1] Goda K, Kikuchi D, Yamamoto Y et al. Endoscopic diagnosis of superficial non-ampullary duodenal epithelial tumors in Japan: Multicenter case series. Dig Endosc 2014; 26 (Suppl. 02): 23-29

[2] Hirashita T, Ohta M, Tada K et al. Prognostic factors of non-ampullary duodenal adenocarcinoma. Jpn J Clin Oncol 2018; 48: 743747
Endoscopy 2022; 54: E544-E545

DOI 10.1055/a-1682-6865

ISSN 0013-726X

published online 15.11.2021

(c) 2021. Thieme. All rights reserved.

Georg Thieme Verlag KG, Rüdigerstraße 14, 70469 Stuttgart, Germany

\section{ENDOSCOPY E-VIDEOS}

https://eref.thieme.de/e-videos

口码 Endoscopy E-Videos is an open access online section, 回梠: reporting on interesting cases and new techniques in gastroenterological endoscopy. All papers include a high quality video and all contributions are freely accessible online. Processing charges apply (currently EUR 375), discounts and wavers acc. to HINARI are available.

This section has its own submission website at

https://mc.manuscriptcentral.com/e-videos 